\title{
Targeting Economic Diversification: An Application of Target MOTAD Procedures
}

\author{
Thomas R. Harris, Chang K. Seung, and Rangesan Narayanan*
}

\begin{abstract}
With rapid change in national, state, and local economies, many economic development agencies and practitioners have attempted to diversify state and local economies to minimize the variability of state and local economic activity. However, minimizing variability may reduce expected economic growth, which may run contrary to the desires of state and/or local officials. This paper applies Minimization of Total Absolute Deviations (MOTAD) and Target Minimization of Total Absolute Deviations (Target MOTAD) for economic diversification plans. MOTAD procedures, which are a linear programming algorithm for portfolio analysis, minimize positive and negative deviations from mean growth rates. Target MOTAD, unlike portfolio variance and MOTAD procedures, minimizes only negative deviations from targeted economic growth rates. Economic diversification plans derived from MOTAD and Target MOTAD procedures are compared and contrasted.
\end{abstract}

\section{INTRODUCTION AND BACKGROUND}

During the 1980s and continuing through the 1990s, many states championed efforts to diversify their economies. With rapid changes in consumer demands, production technology, deregulation of many business sectors, changing emphasis from defense to nondefense manufacturing, and increased trade flows among state and local markets, state and local economies have realized changes in their economic structure. State and local economic development authorities, aware of these structural changes, have attempted to position their local economies to benefit from these changes.

Regions that have their economies in one or a few economic sectors have experienced large swings in economic activity. Economic development practitioners faced with instability often seek to diversify their local economies. However, reducing instability may also reduce gains from trade from their specialized industries, which have a comparative advantage. Therefore, state and local economic development decision makers must balance state and/or local economic stability with growth. Given the desire of numerous state and local decision makers to stabilize their state and/or local economies while maintaining economic growth, the primary objective of this paper is to derive economic diversification plans that attempt to balance these conflicting goals.

\footnotetext{
*Professor, Department of Applied Economics and Statistics and Director, University Center for Economic Development, University of Nevada, Reno; postdoctoral fellow, Department of Applied Economics and Statistics, University of Nevada, Reno; and Associate Dean for Outreach, College of Agriculture, Biotechnology and Natural Resources and Professor, Department of Applied Economics and Statistics, University of Nevada, Reno. This research was funded by the University of Nevada Agricultural Experiment Station Projects Nos. 5147 and 5149; the University of Nevada Foundation; and the U.S. Department of Commerce, Economic Development Administration, University Center for Economic Development, Grant \#07-66-04987.
} 
First, a synopsis of past economic diversification studies is presented. Second, the impact of non-normal distributions in relation to economic diversification is discussed. Third, Minimization of Total Absolute Deviation (MOTAD) and Target Minimization of Total Absolute Deviations (Target MOTAD) are discussed for economic diversification planning. Finally, economic diversification plans for Elko County in northeastern Nevada are derived using both MOTAD and Target MOTAD procedures.

\section{Economic Diversification Studies}

During the past fifty years, numerous research efforts have attempted to measure regional economic diversification and have targeted economic sectors to reduce economic instability. ${ }^{1}$ Construction of an economic diversification index has been an objective of regional scientists for many years. With such an index, local decision makers could compare the stability of their local economies to economies of similar structure and, if necessary, formulate economic diversification plans.

Early efforts to develop local economic diversification plans were based on the Ogive, or entropy, index (Tress 1938; Hackbart and Anderson 1975). This index measures the degree of deviations from equal proportionate shares by each economic sector of employment, income, value added, or production. Optimal diversification for a locality using this index would mean equal proportional employment, income, value added, or production in each sector of the local economy. Criticisms of the Ogive diversification index are that local diversification index values may change if one-digit or two-digit SIC employment, income, value added, or production data are used and that no economic policy implications may be drawn by basing an economy strictly on equal sectoral proportionate shares.

In a study of U.S. manufacturing business cycles, Borts (1961) developed a national average measure, or coefficient, of specialization. Using the national average measure, a local economy is designated as optimally diversified if the proportionate share of employment, income, value added, or production is similar to that of the nation. Criticisms of the national average measure are that a region's industrial mix may be better than the nation's and that the index ignores the contributions of natural resource endowments of a local economy.

Recent studies have employed financial models of portfolio management to estimate economic diversification of a local economy (Harper and St. Louis 1999; Gilchrist and St. Louis 1991, 1994; Board and Sutcliffe 1991; Schoening and Sweeney 1989; Thompson and Shaffer 1992; Gruben and Phillips 1989; Brewer 1985; Brown and Pheasant 1985; Sherwood-Call 1990; Conroy 1975; Wundt 1992; Wundt and Martin 1993; Hunt and Sheesley 1994). It is argued that when a local economy invests in an industry, it expects a stream of returns, such as employment, income, value added, or output, and that these returns are random. Portfolio theory has been used to target industries in such a way as to bring about economic diversification and stability.

${ }^{1}$ An excellent review of economic diversification literature was presented by Siegel, Johnson, and Alwang (1995). 
In some analyses, diversification plans are derived that maximize expected rates of growth while reducing variance of growth rates. However, other economic diversification studies only minimize the variance of economic sector growth while ignoring economic sector growth rates. If only variance is addressed, policy makers would target economic sectors for economic diversifications that would lower overall economic variation in employment, income, value added, or value of production. Economic sectors that interact or co-vary with other economic sectors and lower overall local economic instability are targeted (Conroy 1975).

Wundt (1992) compared portfolio analysis to other measures of economic diversification (equal distribution index, national average index, percentage of manufacturing employment devoted to durable goods production, and entropy index) and found portfolio procedures to be superior for tracking instability in a region. Also, the portfolio methodology yields information useful to policy makers in the formulation of economic diversification plans. Wundt and Martin (1993) incorporated an input-output model with portfolio procedures to derive a more practical evaluation of industrial expansion scenarios within a region. The incorporation of the interindustry matrix constrains proposed industrial expansion alternatives that are feasible given the technical relationships among industries in a region. Schoening and Sweeney (1992) investigated the use of portfolio variance procedures to reduce instability of existing firms and new firm entrants. For the existing firm scenario, implementation of the results of the portfolio variance model may prove impractical given that existing businesses change very slowly. The application of portfolio procedures for simulating the impacts of a new firm entrance is somewhat promising. Problems still arise, however, such as the likely performance of a new firm in a region and the risk-return preference of the new firm.

Hunt and Sheesley (1994) developed an alternative specification of a regional portfolio diversification problem. Their model allows exogenous changes only for export sectors because activity levels for local industries cannot be set. Therefore, the portfolio variance procedure proposed by Hunt and Sheesley (1994) allows only the activity levels of a choice set of export industries to be chosen.

Wagner and Deller (1993) employed the technical coefficients matrix of a statewide input-output model to derive instability for fifty state economies. The diversity index was derived in three parts: 1) the relative size of the matrix or number of endogenous sectors; 2) the density of the matrix; and 3) a scalar measuring the degree of interindustry linkage. Comparing the diversity index measure to a base economy (such as the U.S.) allows construction of a regional economic diversity index. Criticism of this approach is again that the base for comparison is the national or U.S. economy.

If, however, the expected growth rate is ignored, minimization of variability by itself is an insufficient guide to an economic diversification policy (St. Louis 1980). By developing strategies that only minimize variability in sectoral growth 
rates, the trade-offs between variability (risk) and expected returns or growth, as emphasized in modern portfolio theory, are ignored. Instead of using the portfolio variance measures for diversifying a local economy, Harper and St. Louis (1999) employed Baumol's (1963) likely lower bound procedure, which employs a refinement of the semivariance approach to derive diversification plans for a local economy. Harper and St. Louis (1999) found that the portfolio variance measure yielded an unwarranted degree of risk aversion, which may produce inappropriate local economic development targets.

\section{Minimization of Total Absolute Deviations}

An alternative to portfolio variance modeling is the Minimization of Total Absolute Deviations (MOTAD) procedures, as developed by Hazell (1971). In the MOTAD model, risk is measured as linear deviations from the mean. Risk is assumed undesirable and therefore minimized. The trade-off occurs between mean values (E) and deviation from the mean value (A). The E-A frontier is developed by parametrically running the model with regard to mean values and minimization of absolute deviations from the mean values.

In comparison with portfolio variance procedures where one minimizes variance subject to constraints, MOTAD procedures minimize absolute deviations from mean values subject to constraints. Therefore, MOTAD procedures can be stated mathematically as:

Subject to:

$$
\operatorname{Min}: \mathrm{Z}_{\mathrm{o}}=\sum_{\mathrm{h}=1}^{\mathrm{s}}\left(\mathrm{y}_{\mathrm{h}}^{+}+\mathrm{y}_{\mathrm{h}}^{-}\right)
$$

$$
\begin{array}{ll}
\sum_{j=1}^{n} a_{i j} x_{j} \leq b_{i} & i=1,2, \ldots, m \\
\sum_{j=1}^{n}\left(C_{h j}-\bar{C}_{j}\right) x_{j}-y_{h}^{+}+y_{h}^{-}=0 & h=1,2, \ldots, s
\end{array}
$$

Where:

$$
\sum_{j=1}^{n} \bar{C}_{j} X_{j}=\lambda
$$

$\mathrm{y}_{\mathrm{h}}^{+}$is positive deviations from the mean return;

$\mathrm{y}_{\mathrm{h}}^{-}$is negative deviations from the mean return;

$a_{i j}$ is the technical requirements for activity $j$ for resource or constraint $i$;

$X_{j}$ is the level of activity $j$;

$b_{i}$ is the level of resource or constraint $i$;

$\mathrm{C}_{\mathrm{hj}}$ is the observed return for activity $\mathrm{j}$ in time period $\mathrm{h}$;

$\bar{C}_{j}$ is the expected or average return for activity $j$;

$\lambda$ is the parameterized value of expected returns; and

$\mathrm{s}$ is the number of time periods. 
Since deviations are measured from the mean return, total negative deviations must equal total positive deviations. Therefore, the MOTAD model can be developed where only negative deviations or positive deviations are minimized.

\section{Target Minimization of Total Absolute Deviations}

The Target Minimization of Total Absolute Deviations, or Target MOTAD, as developed by Tauer (1983) and Watts, Held, and Helmers (1984), provides an alternative procedure for incorporating risk in the objective function. In Target MOTAD, risk is defined as the absolute value of deviations below a fixed target. The target can be fixed at any level from which risk is to be measured. The ability to measure risk from an independent reference point, rather than the mean, is an advantage of Target MOTAD over mean-variance or MOTAD procedures. Target MOTAD has been used in agricultural marketing (McKinnell, Kahl, and Curtis 1990; Curtis et al. 1987), agricultural production planning incorporating risk (Vandeveer, Paxton, and Lavergne 1989; Parton and Cumming 1990; Novak, Mitchell, and Crews 1990) and agricultural production planning incorporating environmental targets (Teague, Bernardo, and Mapp 1995a, b).

Unlike portfolio variance or MOTAD procedures, which minimize both positive and negative deviations from the mean, and semivariance programming, which minimizes only negative deviations from the mean, Target MOTAD minimizes only negative deviations from a specified target. Economic development practitioners are more concerned with negative deviations from a specified targeted annual rate of growth rather than with positive deviations from a target. In addition, development practitioners may have little aversion to deviations above target growth rates or the mean growth rate in portfolio variance or MOTAD procedures. It could easily be argued that development practitioners would be less or not risk averse to programs or policies that would realize positive deviations from a target as in Target MOTAD. Target MOTAD fits more closely the concerns of economic development practitioners.

An additional advantage of the Target MOTAD model is that its solutions are second degree stochastically efficient (Tauer 1983). Stochastic dominance has been used in numerous financial studies (Porter and Carey 1974; Hadar and Russell 1974; Porter, Wart, and Ferguson 1973) and agricultural production studies (Kramer and Pope 1981; Harris and Mapp 1986; King and Robinson 1981) to derive risk-efficient portfolios and agricultural production plans. Stochastic dominance does not require a preference function for risk to be elicited or distribution of returns to be assigned. Stochastic dominance allows analysis beyond the mean and variance of a distribution by focusing on the tails of the distribution. The ability of Target MOTAD to incorporate properties of stochastic dominance is a unique feature not available through Baumol's (1963) lower confidence limit criteria. Therefore, economic diversification plans derived through Target MOTAD procedures are estimated not only during average conditions but also at the tails of the distribution where the worst conditions occur. A stochastically dominated 
economic targeting scenario not only yields the highest regional employment growth, but is also less prone to low outcomes during times of lower regional economic activity.

For mean-variance analysis, quadratic programming algorithms must be used. However, quadratic programming algorithms may not be readily available and often are difficult in their application. Additionally, post-optimality analysis using quadratic programming procedures is difficult if not impossible with some algorithms. MOTAD and Target MOTAD procedures, however, employ linear programming procedures to derive stochastically efficient solutions. Unlike quadratic programming algorithms, the variance-covariance matrix is not required. Also, post-optimality analysis is easily completed using linear programming procedures.

The Target MOTAD model is stated mathematically as:

$$
\operatorname{Max}: \mathrm{Z}_{0}=\sum_{\mathrm{j}=1}^{\mathrm{n}} \overline{\mathrm{C}}_{\mathrm{j}} \mathrm{X}_{\mathrm{j}}
$$

Subject to:

Where:

$$
\begin{array}{lr}
\sum_{j=1}^{n} a_{i j} X_{j} \leq b_{i} & i=1,2, \ldots, m \\
T-\sum_{j=1}^{n} C_{h j} X_{j}-Y_{h} \leq 0 & h=1,2, \ldots, s \\
\sum_{h=1}^{s} P_{h} Y_{h}=\lambda &
\end{array}
$$

$T$ represents the target level of returns;

$Y_{h}$ is the deviation below the target level $T$ in time period $h$;

$P_{h}$ represents a probability of state of nature $h\left(P_{h}=1 / s\right)$;

$\bar{C}_{j}$ is the return of activity $j$;

$\mathrm{C}_{\mathrm{hj}}$ is the return of activity $\mathrm{j}$ in time period $\mathrm{h}$;

$\lambda$ is the expected deviation below the target level and is parameterized from zero to some large number;

$s$ is the total number of time periods considered; and

$\mathrm{X}_{\mathrm{i}}, \mathrm{a}_{\mathrm{ij}}$, and $\mathrm{b}_{\mathrm{i}}$ are as previously defined.

\section{STUDY AREA}

Using both MOTAD and Target MOTAD procedures, economic diversification plans were estimated for Elko County, Nevada. Like many western U.S. counties, Elko County is characterized as having a "boom-bust" economy. Elko County's primary industry is gold mining, which is currently experiencing a slowdown after years of expansion. In addition, neighboring Eureka County has opened a new gold mining operation. Population in Elko County grew from 17,550 in 1980 to 34,146 in 1990 and 45,534 in 1997, a 159.45 percent increase in seventeen years (Nevada State Demographer's Office 2000). 
The level of gold mining activity is influenced by available resources and international gold prices. Additionally, Elko County has substantial public lands (approximately 71.5 percent of total Elko County acreage is administered by the federal government) whose use is regulated by the federal government. Currently the federal government is reconsidering grazing fees and permits, mineral royalties, and other uses of the public lands. Revised fees, permits, royalties, and/or use permits will impact current operations by agricultural and mining sectors as well as the local tourism industry. Given the potential instability of these primary sectors, plans to diversify the economy are of interest to economic development decision makers in Elko County. Table 1 shows sectoral mean, standard deviation, coefficient of variation, coefficient of skewness, and coefficient of kurtosis values for employment growth rates in Elko County from 1969 to $1997 .^{2}$

\section{TABLE 1}

Sectoral Average Employment Growth, Standard Deviation, Coefficient of Variation, Coefficient of Skewness, and Coefficient of Kurtosis for Elko County, Nevada, 1969-1997

\begin{tabular}{|c|c|c|c|c|c|}
\hline Sector & $\begin{array}{c}\text { Average } \\
\text { Annual } \\
\text { Growth Rate }\end{array}$ & $\begin{array}{l}\text { Standard } \\
\text { Deviation }\end{array}$ & $\begin{array}{l}\text { Coefficient } \\
\text { of Variation }\end{array}$ & $\begin{array}{l}\text { Coefficient } \\
\text { of Skewness }\end{array}$ & $\begin{array}{l}\text { Coefficient } \\
\text { of Kurtosis }\end{array}$ \\
\hline Agriculture & 0.0058 & 0.0769 & 13.2589 & 0.2430 & -0.1864 \\
\hline Mining & 0.1108 & 0.2388 & 2.1552 & $0.9998^{*}$ & $0.7037^{*}$ \\
\hline Construction & 0.0861 & 0.2261 & 2.6260 & 0.7294 & 0.1960 \\
\hline Manufacturing & 0.0692 & 0.1993 & 2.8801 & $1.6783^{*}$ & $4.7363^{*}$ \\
\hline $\begin{array}{l}\text { Transportation, } \\
\text { Communications, }\end{array}$ & 0.0229 & 0.0686 & 2.9956 & 0.0859 & -1.1870 \\
\hline Wholesale Trade & 0.0660 & 0.1531 & 2.3197 & $0.7783^{*}$ & 2.5343 \\
\hline Retail Trade & 0.0416 & 0.0568 & 1.6346 & $1.0226^{*}$ & 1.3793 \\
\hline $\begin{array}{l}\text { Finance, Insurance, } \\
\text { and Real Estate }\end{array}$ & 0.0427 & 0.1140 & 2.6698 & $1.4448^{*}$ & $5.5089^{*}$ \\
\hline Services & 0.0729 & 0.0622 & 0.8532 & $2.3171^{*}$ & $7.9954^{*}$ \\
\hline Elko County & 0.0493 & 0.0411 & 0.8337 & 0.5618 & 0.6751 \\
\hline
\end{tabular}

*Reject the hypothesis of normality at the 0.10 level.

Coefficient of skewness and coefficient of kurtosis were calculated to determine if growth rates were distributed non-normally. If skewness or kurtosis exist, portfolio analysis, which assumes growth rates to be distributed normally and a quadratic utility of risk, would apply unwarranted risk aversion to the targeted industry analysis.

Figure 1 shows the variability of annual employment growth in Elko County. The annual rate of employment growth in Elko County was as high as 16.03 percent in 1985 and as low as -2.49 percent in 1975 . Over the twenty-seven year study period, overall employment growth in Elko County averaged approximately 4.9 percent.

${ }^{2}$ Employing sectoral growth rates instead of sectoral employment levels has been found to induce stationarity in many economic series. Growth rates were used in regional portfolio analysis by St. Louis (1980), Brown and Pheasant (1985), and Hunt and Sheesley (1994). 
FIGURE 1

Annual Employment Growth Rates for Elko County, Nevada, 1969 to 1997

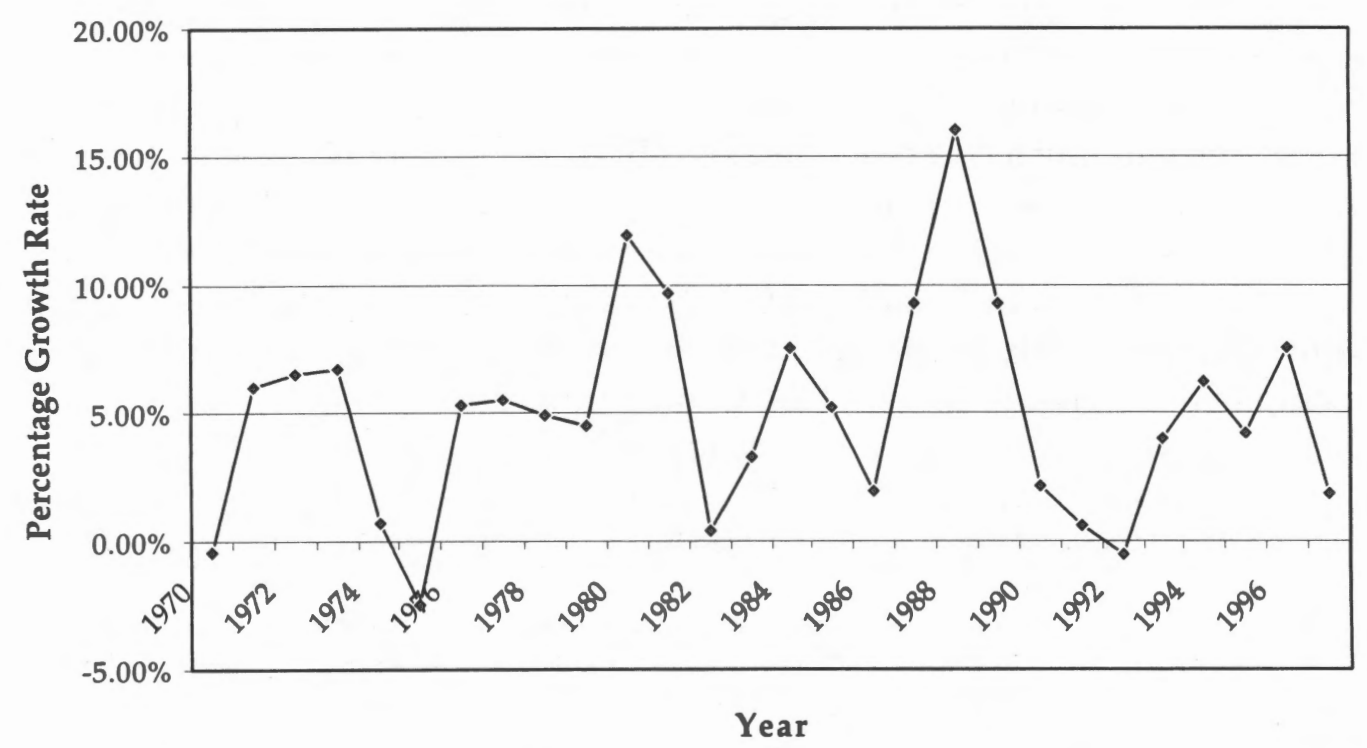

Sectoral analysis was aggregated to the basic one-digit SIC categories. This aggregation follows the suggestion by Harper and St. Louis (1999) to avoid the issue of picking winners from sectors that comprise small fractions of the labor force and thereby focus on the issue of diversification among major economic sectors.

To develop a MOTAD model for economic diversification plans, the model can be stated mathematically as:

$$
\operatorname{Min}: \mathrm{Z}_{\mathrm{o}}=\sum_{\mathrm{h}=1}^{s}\left(\mathrm{y}_{\mathrm{h}}^{+}+\mathrm{y}_{\mathrm{h}}^{-}\right)
$$

Subject to:

$$
\sum_{j=1}^{n} x_{j}=1.0
$$

$$
\sum_{j=1}^{n}\left(C_{h j}-\bar{C}_{j}\right) x_{j}-y_{h}^{+}+y_{h}^{-}=0 \quad h=1,2, \ldots, s
$$

$$
\sum_{j=1}^{s} \bar{C}_{j} X_{j}=\lambda
$$

$$
1_{j} \leq X_{j} \leq u_{j}
$$$$
\mathrm{j}=1,2, \ldots, \mathrm{n}
$$

Where:

$\mathrm{X}_{\mathrm{j}}$ is the proportionate share of economic sector $\mathrm{j}$;

$y_{h}^{+}$is positive deviation above county average rate in time period $h$;

$y_{h}^{-}$is negative deviation below county average rate in time period $h$;

$\mathrm{C}_{\mathrm{hj}}$ is the growth rate of sector $\mathrm{j}$ in time period $\mathrm{h}$; 
$\bar{C}_{j}$ is average growth rate in sector $j$;

$l_{j}$ is the lower proportionate share limit for sector $j$; and

$u_{j}$ is the upper proportionate share limit for sector $j$.

To test for normality, the Wald statistic as described by Jarque and Bera (1980) can be used. Under the null hypothesis of normality, i.e., skewness equal to zero and kurtosis equal to three, the Wald statistic is asymptotically distributed as a chi-squared distribution (Greene 1997). However, a drawback of basing tests on measures of skewness and kurtosis is that their behavior may be rather erratic in small samples. Given that there were only twenty-eight observations in this analysis, nonparametric tests were used to test normality. The Shapiro-Wilks test was employed to test for normality of calculated skewness while the KolmogorovSmirnov procedures were employed to test for normality of calculated kurtosis.

The Kolmogorov-Smirnov test is based on the maximum distance between the sample cumulative density function and the normal cumulative density function. The Shapiro-Wilks test is closely aligned with the normal probability plot, since the test is based on correlations between normal quantities and the sample quantities. The correlation measures how close the normal plot is to being a straight line (Minitab, Inc. 1966).

Table 1 shows that the mining sector had the highest average annual growth rate of employment at approximately 11 percent, while the agricultural sector yielded the largest coefficient of variation. Six economic sectors displayed non-normal skewness while four economic sectors displayed non-normal kurtosis.

Some of the sectoral growth rates in Elko County are non-normally distributed and the risk function is not quadratic. Economic diversification plans derived through quadratic programming may be incorrect by overestimating or underestimating optimal economic diversification plans in a particular sector. For this analysis, a Target MOTAD model is used to derive economic diversification plans for Elko County. The model for Elko County is stated mathematically as:

$$
\operatorname{Max}: E(Z)=\sum_{j=1}^{n} \bar{C}_{j} X_{j}
$$

Subject to:

$$
\begin{aligned}
& \sum_{j=1}^{n} X_{j}=1.0 \\
& T-\sum_{j=1}^{n} C_{h j} X_{j}-Y_{h} \leq 0 \quad h=1,2, \ldots, s \\
& \sum_{h=1}^{s} P_{h} Y_{h}=\lambda \\
& l_{j} \leq X_{j} \leq u_{j} \text { for all } j
\end{aligned}
$$


Where:

$\bar{C}_{j}$ is the expected or average growth rate of sector $j$;

$\mathrm{C}_{\mathrm{hj}}$ is the growth rate of sector $\mathrm{j}$ in time period $\mathrm{h}$;

$\mathrm{T}$ is the target growth rate;

$Y_{h}$ is the allowable deviation below the target growth rate for time period h;

$P_{h}$ is the probability of period $h\left(P_{h}=1 / s\right)$;

$s$ is the total number of time periods;

$\lambda$ is the expected deviation below the target rate; and

$X_{j}, u_{j}$, and $l_{j}$ are as previously defined.

Equation 14 is the objective function that maximized the expected employment growth rate in Elko County. The first constraint, Equation 15, requires the sum of shares of all sectors to be equal to one. Constraint Equation 16 requires that for each time period the weighted average growth rate must meet the target growth rate with consideration of the tolerance deviation. The third constraint, Equation 17, sums the negative employment growth rate deviations times their probability of occurrence. For this paper, $P_{h}=1 / \mathrm{s}$. The sum is represented by parameter $\lambda$, which should be loosely interpreted as the expected deviation below the target employment growth rate. The model successfully solves by varying $\lambda$ from zero to a large number. When $\lambda$ is sufficiently large, the model is equivalent to a deterministic linear programming model. For $\lambda$ equal to zero, no negative employment growth rate deviations are allowed in any time period, which is analogous to the safety first decision rule. Constraint Equation 18 sets a lower and upper limit on proportionate share an economic sector may have.

Harper and St. Louis (1999) and Schoening and Sweeney (1992) suggest that adjacent counties with similar economic base be used to formulate desired economic development strategies. To estimate economic base of a given county economy, location quotient procedures were employed. Table 2 shows the calculated location quotients for the Nevada counties of Elko and Humboldt and the Idaho county of Twin Falls.

TABLE 2

Location Quotients for Elko and Humboldt Counties in Nevada and Twin Falls County in Idaho, 1997

\begin{tabular}{lccc}
\hline Sector & $\begin{array}{r}\text { Elko County, Nevada } \\
\text { Nevada }\end{array}$ & $\begin{array}{c}\text { Humboldt County } \\
\text { Nevada }\end{array}$ & $\begin{array}{c}\text { Twin Falls County } \\
\text { Idaho }\end{array}$ \\
\hline Agriculture & 1.08 & 1.96 & 2.89 \\
Mining & 10.39 & 41.10 & 0.59 \\
Construction & 1.19 & 1.09 & 1.19 \\
Manufacturing & 0.09 & 0.12 & 0.80 \\
Transportation, Communications, & & & \\
and Public Utilities & 0.83 & 0.98 & 1.05 \\
Wholesale Trade & 0.83 & 0.53 & 1.04 \\
Retail Trade & 0.88 & 0.88 & 1.24 \\
Finance, Insurance, and Real Estate & 0.49 & 0.39 & 0.64 \\
Services & 1.39 & 0.74 & 0.81 \\
\hline
\end{tabular}


Table 2 shows that the economic base sectors of Elko and Humboldt Counties are quite similar, with the mining sector being the primary export sector. However, the mining sector is characterized as a "boom-bust" industry, so its expected annual change in employment is quite high. The rural economies of Elko County, Nevada, and Twin Falls County, Idaho, are somewhat different, with Twin Falls County currently being a commercial sector center. However, during recent years, Elko County has tried to compete with Twin Falls County as a commercial sector center for this area of the mountain states. Therefore, to incorporate the suggestions of Harper and St. Louis (1999) and Schoeing and Sweeney (1992) while providing the potential of a commercial trade center, the three counties of Elko, Humboldt, and Twin Falls will be used to derive upper and lower limits for sectoral employment shares (Table 3).

\section{TABLE 3}

Sectoral Proportionate Shares of Total Employment for Elko and Humboldt Counties in Nevada and Twin Falls County in Idaho, 1997

\begin{tabular}{lccc}
\hline Sector & $\begin{array}{c}\text { Elko County, } \\
\text { Nevada (\%) }\end{array}$ & $\begin{array}{c}\text { Twin Falls County, } \\
\text { Idaho (\%) }\end{array}$ & $\begin{array}{c}\text { Humboldt County, } \\
\text { Nevada (\%) }\end{array}$ \\
\hline Agriculture & 4.02 & 10.58 & 7.65 \\
Mining & 7.25 & 0.37 & 26.61 \\
Construction & 7.30 & 7.37 & 6.71 \\
Manufacturing & 1.29 & 11.49 & 2.57 \\
Transportation, & & & \\
Communications, & 4.62 & 5.88 & 5.50 \\
and Public Utilities & 4.42 & 5.56 & 3.27 \\
Wholesale Trade & 17.18 & 24.24 & 18.09 \\
Retail Trade & & & \\
Finance, Insurance, & & 5.63 & 2.96 \\
and Real Estate & 4.22 & 28.88 & 26.63 \\
Services & 49.70 & 100.00 & 100.00 \\
Total & 100.00 & & \\
\hline
\end{tabular}

\section{RESULTS}

Economic diversification strategies for Elko County were derived using MOTAD and Target MOTAD procedures. Table 4 shows the risk pairs from the MOTAD procedures. Results from Table 4 show that as risk increases (summation of negative deviations from the mean), mean annual employment growth increases, which yields the E-A frontier. Along the E-A frontier, like the E-V frontier of portfolio variance, economic diversification plans are derived, which maximize expected employment growth rates while minimizing risk.

At lower growth rates (5 percent), the three major economic sectors for Elko County are service, retail trade, and agriculture. However, as growth increases, risk likewise increases. The mining sector proportionate share of total employment increases from 0.74 percent at a 5.0 percent growth rate to 25.37 percent at a 6.6 percent growth rate. 


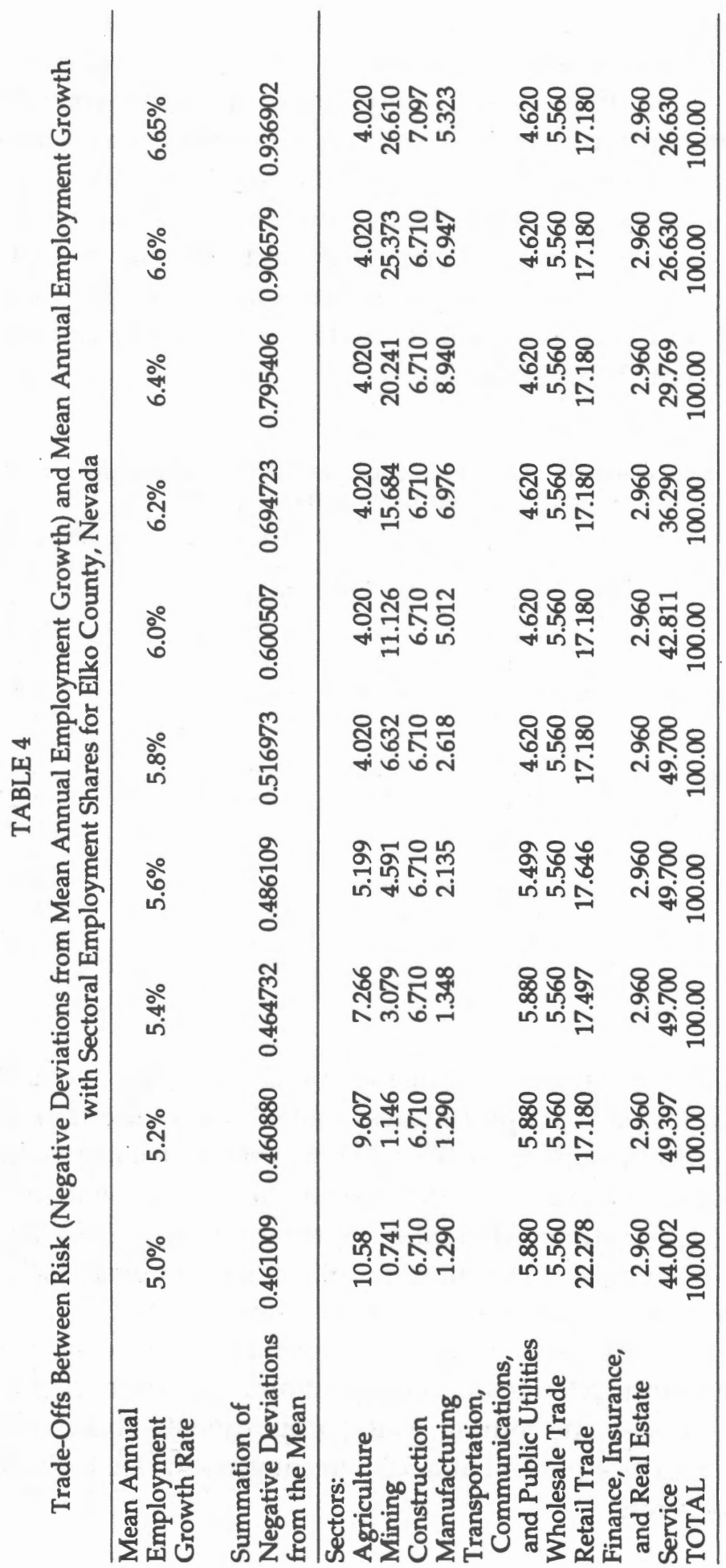




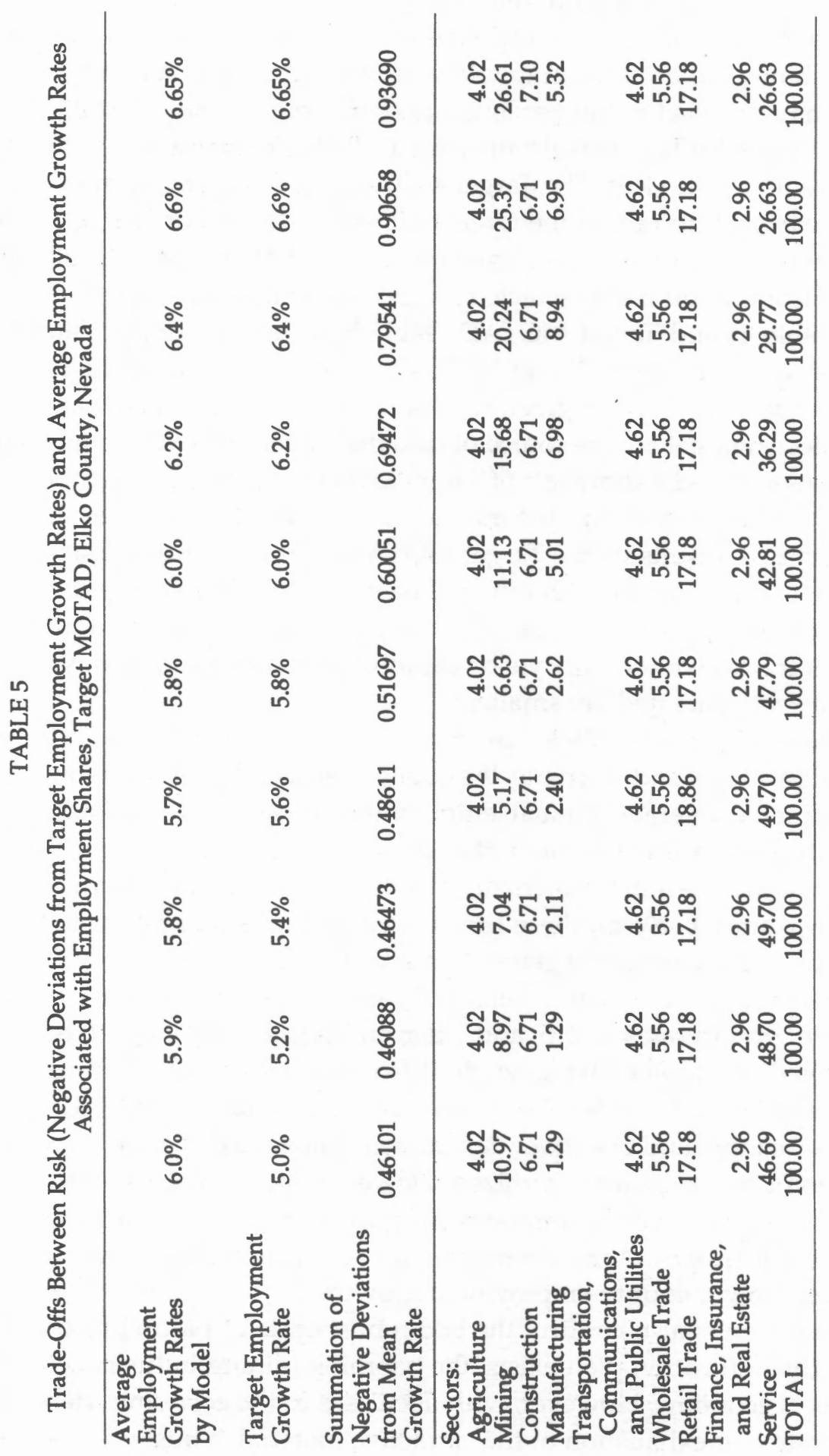


Results of the MOTAD procedures follow the hypothesis of Gilchrist and St. Louis (1991) and Harper and St. Louis (1999.) These studies suggest that movements to diversify regional economies away from their comparative advantage in natural resource industries (such as Elko County diversifying away from the mining sector) may yield an undesirably low growth rate. The instability of the mining sector may be offset by higher levels of employment growth for Elko County.

The Target MOTAD results presented in Table 5 correspond to the MOTAD results presented in Table 4. The Target MOTAD results were generated by using MOTAD mean growth rate as the target and setting the maximum negative deviations at the same level as in the corresponding MOTAD solution. If only negative deviations from a properly selected target generated risk, then the last six MOTAD (Table 4) and Target MOTAD (Table 5) solutions are equivalent in risk. For the first four solutions, Target MOTAD solutions generated higher average employment growth rates for given risk value. If only negative deviations from a correctly selected target are the source of risk, the Target MOTAD model is superior.

Tables 6, 7, and 8 show sets of Target MOTAD solutions developed for each target level by parameterizing the maximum negative deviation level. However, before discussing results of the Target MOTAD solutions, a discussion of procedures to select the target growth rate will be presented. Procedures developed by Berbel (1990) were followed to calculate a range of target growth rates. A target that is either too low or too high yields solutions that lack the risk dimension, thus the efficient sets generated are smaller.

Following Berbel's (1990) procedures, a range of targets is derived. By solving the problem and deriving the highest expected growth rate, the upper limit for targeted average annual employment growth rate is found. For this paper, the highest annual growth rate derived was 10.28 percent. Solving the model again as a max-min problem derives the lowest annual growth rate of 0.164 percent. Any target between these limits is valid, but use of a target close to the max-min has the advantage of generating a larger efficient set.

Tables 6, 7, and 8 show results of Target MOTAD procedures for targeted employment growth rates of 2,5 , and 7 percent. Results from each target of interest are derived where negative deviations from the target are minimized. Results of the Target MOTAD and MOTAD differ because in Target MOTAD only negative (versus positive and negative) deviations from a fixed (versus a moving) risk reference point or target are minimized. However, for each result, it is again seen that to have higher levels of employment growth, the employment share of the mining sector increases. Again, economic diversification efforts away from mining may yield lower county employment growth.

These results also confirm the boom-bust cycle of natural resource industries. If no diversification plan exists, the booming mining industry will predominate the local economy. However, with decreases in the economic viability of the natural resource or exhaustion of the extractive material, a bust will follow. These trade-offs must be considered by local economic development decision makers. 
TABLE 6

Sectoral Employment Shares, Expected Rates of Growth, and Summation of Negative Deviations from Targeted Growth Rate with Annual Growth Rate Target of $2 \%$ for Elko County, Nevada

Average Employment

Growth Rate

$5 \%$

$5.5 \%$

$6.0 \%$

$6.5 \%$

1997 Shares

Summation of Negative

Deviations from

Mean Growth Rate $\begin{array}{llll}0.00598 & 0.00646 & 0.00804 & 0.01166\end{array}$

Sectors:

Agriculture

Mining

Construction

Manufacturing

Transportation,

Communications, and Public Utilities

Wholesale Trade

Retail Trade

8.15

0.37

6.71

4.02

(Percentage)

4.02
10.58

2.58

10.58

7.37

7.37

11.49

4.02

22.72

22.72
7.37

11.23

4.02

1.29

2.77

11.23

7.23

7.32

1.29

Finance, Insurance,

and Real Estate

5.88

4.62

4.62

4.62

4.62

3.27

3.27

3.27

3.27

4.42

24.24

20.04

17.18

17.18

17.18

Services

5.63

5.63

2.96

2.96

4.22

TOTAL

44.46

49.70

38.51

26.63

49.70

100.00

100.00

100.00

100.00

100.00

\section{TABLE 7}

Sectoral Employment Shares, Expected Rates of Growth, and Summation of Negative Deviations from Targeted Growth Rate with Annual Growth Rate Target of 5\% for Elko County, Nevada

Average Employment

Growth Rate

$5 \%$

$5.5 \%$

$6.0 \%$

$6.5 \%$

1997 Shares

Summation of Negative

Deviations from

Mean Growth Rate 0.01636 0.01567

0.01845 0.02224

Sectors:

Agriculture

9.77

0.37

4.02 (Percentage)

Mining

6.71

1.40

4.02

9.83

7.37

Manufacturing

1.29

7.37

11.49

4.02

4.02

22.23

7.23

Transportation,

3.61

7.37

7.32

Communications, and Public Utilities

4.62

4.62

4.62

4.62

Wholesale Trade

Retail Trade

3.27

5.56

5.56

5.56

4.42

Finance, Insurance, and Real Estate

19.97

19.46

17.18

17.18

17.18

Services

5.63

5.63

2.96

2.96

4.22

TOTAL

100.00

100.00

100.00


TABLE 8

Sectoral Employment Shares, Expected Rates of Growth, and Summation of Negative Deviations from Targeted Growth Rate with Annual Growth Rate Target of 7\% for Elko County, Nevada

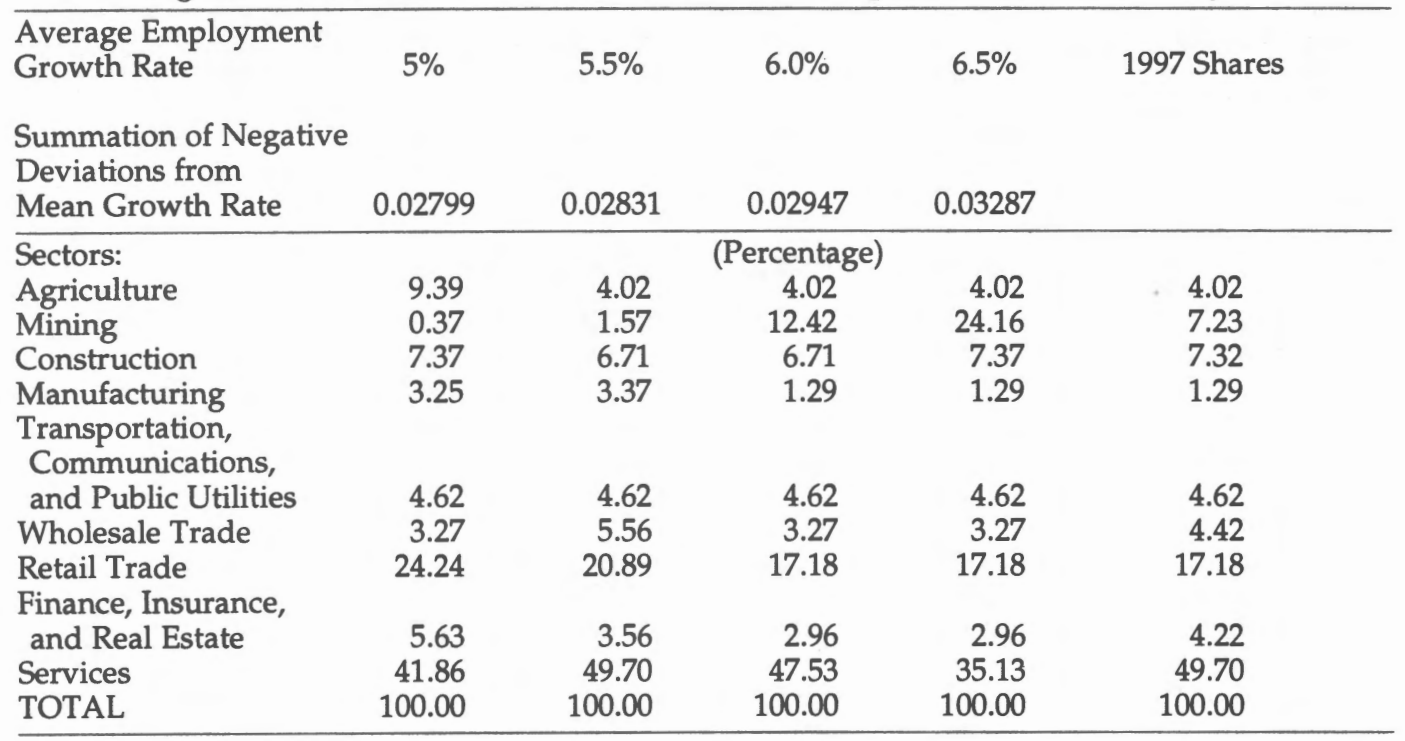

\section{CONCLUSION}

The purpose of this paper was to estimate the trade-off between risk and return in formulating economic diversification plans for a rural northeastern Nevada county. Numerous studies have investigated numerical procedures to estimate economic instability. One such numerical tool is MOTAD, which is a linearization of portfolio variance models. However, analyzing trade-offs between risk and average growth rates is subject to question since risk is dependent on average growth risks. In most cases, the only way to reduce risk in MOTAD or portfolio variance models is to reduce employment growth rates. From a practical standpoint, local economic decision makers do not see high growth rates as a threat, whereas low growth rates yielding negative deviations from an acceptable fixed growth rate are a problem.

Also, the Target MOTAD has beneficial attributes over the Baumol (1963) likely lower bound procedure. The main advantage is that Target MOTAD seeks to minimize only negative deviations, rather than a variance of positive and negative deviations, from a fixed risk point or target rather than a moving mean or target.

Because of non-normality of sectoral growth rates and the desire of local economic development officials to meet or exceed a selected growth rate, the Target MOTAD procedures may be more desirable in formulating local economic diversification goals. Also following multi-objective modeling procedures outlined by Teague, Bernardo, and Mapp (1995a, b), Target MOTAD models can be developed to consider multiple goals, such as income growth and environmental targets. 
Results of the Target MOTAD model indicate that economic diversification plans that target diversification alone may lead rural economies away from local economic sectors that have comparative advantage and to economic diversification plans that would yield low growth rates. Regions that have resource endowments such as mineral deposits may find that economic diversification efforts away from the mining sector may lower potential economic activity. Target MOTAD gives economic development practitioners insights as to the trade-offs between economic instability and growth. As noted by Harper and St. Louis (1999), results of the Target MOTAD model indicate that theories of Ricardo should not be forgotten and these theories should be incorporated into local economic development and diversification strategies.

\section{REFERENCES}

Baumol, William J. "An Expected Gain-Confidence Limit Criterion for Portfolio Selection." Management Science 10 (1963), 174-182.

Berbel, Julio. "A Comparison of Target MOTAD Efficient Sets and the Choice of Target." Canadian Journal of Agricultural Economics 38 (1990), 149-158.

Board, J., and C. Sutcliffe. "Risk and Income Tradeoffs in Regional Policy: A Portfolio Theory Approach." Journal of Regional Science 31 (1991), 191-210.

Borts, G.H. "Regional Cycles of Manufacturing Employment in the U.S., 1914-53."

National Bureau of Economic Research Occasional Paper No. 75, New York, 1961.

Brewer, H.L. "Measures of Diversification: Predictors of Regional Economic Instability." Journal of Regional Science 25 (1985), 463-470.

Brown, D.J., and J. Pheasant. "A Sharpe Portfolio Approach to Regional Economic Analysis." Journal of Regional Science 25 (1985), 51-63.

Conroy, M.E. "The Concept and Measurement of Regional Industrial Diversification." Southern Economics Journal 41 (1975), 492-505.

Curtis, C.E., G.H. Pfeiffer, L.L. Lutgen, and S.D. Frank. "A Target MOTAD Approach to Marketing Strategy Selection for Soybeans." North Central Journal of Agricultural Economics 9 (1987), 195-206.

Gilchrist, D.A., and L.V. St. Louis. "Directions for Diversification with an Application to Saskatchewan." Journal of Regional Science 31 (1991), 273-289.

"An Equilibrium Analysis of Regional Industrial Diversification."

Regional Science and Urban Economics 24 (1994), 115-133.

Greene, W.H. Econometric Analysis. 3rd ed. New York: MacMillan Publishing Company, 1997.

Gruben, W.C., and K.R. Phillips. "Diversifying Texas: Recent History and Prospects." Federal Reserve Bank of Dallas Economic Review (1989), 1-12. Hackbart, M.M., and D.A. Anderson. "On Measuring Economic Diversification." Land Economics 51 (1975), 374-378.

Hadar, J., and W. Russell. "Stochastic Dominance and Diversification." Journal of Economic Theory 7 (1974), 231-240. 
Harper, Deborah J., and Larry V. St. Louis. "Regional Economic Diversification and Efficiency: Baumol's Likely Lower Confidence Limit Measure of Risk." The Review of Regional Studies 29 (1999), 197-211.

Harris, T.R., and H.P. Mapp, Jr. "A Stochastic Dominance Comparison of WaterConserving Irrigation Strategies." American Journal of Agricultural Economics 68 (1986), 289-305.

Hazell, P.B.R. "A Linear Alternative to Quadratic and Semivariance Programming for Farm Planning under Uncertainty." American Journal of Agricultural Economics 53 (1971), 53-62.

Hunt, G.L., and T.J. Sheesley. "Specification and Econometric Improvements in Regional Portfolio Diversification Analysis." Journal of Regional Science 34 (1994), 217-235.

Jarque, C.M., and A.K. Bera. "Efficient Tests for Normality, Homoscedasticity and Serial Independence of Regression Residuals." Economics Letters 6 (1980), 255-259.

King, R.P., and L.J. Robinson. "An Interval Approach to Measuring Decision Maker Preferences." American Journal of Agricultural Economics 63 (1981), 510-520.

Kramer, R.A., and R.D. Pope. "Participation in Farm Commodity Programs: A Stochastic Dominance Analysis." American Journal of Agricultural Economics 63 (1981), 119-128.

McKinnell, C.S., K.H. Kahl, and C.E. Curtis, Jr. "A Regional Comparison of RiskEfficient Soybean Marketing Strategies." Southern Journal of Agricultural Economics 22 (1990), 167-176.

Minitab, Inc. MINITAB Reference Manual Release II for Windows. State College, PA, 1996.

Nevada State Demographer's Office. "1999 Nevada Population Estimates for Counties, Cities and Unincorporated Towns." Reno: University of Nevada, Reno, 2000.

Novak, J.L., C.C. Mitchell, Jr., and J.R. Crews. "Risk and Sustainable Agriculture: A Target MOTAD Analysis of the 92-Year Old Rotation." Southern Journal of Agricultural Economics 22 (1990), 145-153.

Parton, K.A., and R.J. Cumming. "An Application of Target MOTAD Programming to the Analysis of Downside Business and Financial Risk on Farm." Review of Marketing and Agricultural Economics 58 (1990), 76-88.

Porter, R.B., J.R. Wart, and D.L. Ferguson. "Efficient Algorithms for Conducting Stochastic Dominance Tests of Large Numbers of Portfolios." Journal of Financial and Quantitative Analysis 8 (1973), 71-81.

Porter, R.B., and K. Carey. "Stochastic Dominance as a Risk Analysis Criterion." Decision Science 5 (1974), 10-21.

Schoening, N.C., and L.E. Sweeney. "Applying an Industrial Diversification Decision Model to Small Regions." The Review of Regional Studies 19 (1989), 14-17. . "Proactive Industrial Development Strategies and Portfolio Analysis." The Review of Regional Studies 22 (1992), 227-238. 
Sherwood-Call, C. "Assessing Regional Economic Stability: A Portfolio Approach." Federal Reserve Bank of San Francisco Economic Review (1990), 17-26.

Siegel, P.B., T.G. Johnson, and J. Alwang. "Regional Economic Diversity and Diversification: Seeking a Framework Analysis." Growth and Change 26 (1995), 261-284.

St. Louis, L.V. "A Measure of Regional Diversification and Efficiency." Annals of Regional Science 14 (1980), 21-30.

Tauer, L.M. "Target MOTAD." American Journal of Agricultural Economics 65 (1983), 606-610.

Teague, M.L., D.J. Bernardo, and H.P. Mapp, Jr. "Meeting Environmental Goals Efficiently on a Farm-Level Basis." Review of Agricultural Economics 17 (1995a), 37-50.

. "Farm-Level Economic Analysis Incorporating Stochastic Environmental Risk Assessment." American Journal of Agricultural Economics 77 (1995b), 8-19.

Thompson, E., and R. Shaffer. "An Occupationally Constrained Portfolio Targeting Model: An Application in Wisconsin Regions." Selected Paper for the Regional Science Association International, Chicago, IL, 1992.

Tress, R.C. "Unemployment and Diversification of Industry." The Manchester School 9 (1938), 140-152.

Vandeveer, L.R., K.W. Paxton, and D.R. Lavergne. "Irrigation and Potential Diversification Benefit in Humid Climates." Southern Journal of Agricultural Economics 21 (1989), 167-174.

Wagner, J.E., and S.C. Deller. "A Measure of Economic Diversity: An Input-Output Approach." U.S. Department of Agriculture Forest Service, Southeastern Forest Experiment Station, Staff Paper 93.3. Research Triangle, NC, 1993.

Watts, M.J., L. Held, and G. Helmers. "A Comparison of Target-MOTAD to MOTAD." Canadian Journal of Agricultural Economics 32 (1984), 175-185.

Wundt, B.D. "Re-Evaluating Alternative Measures of Industrial Diversity as Indicators of Regional Cyclical Variations." The Review of Regional Studies 22 (1992), 59-74.

Wundt, B.D., and L.R. Martin. "Minimizing Employment Instability: A Model of Industrial Expansion with Input-Output Considerations." Regional Science Perspectives 23 (1993), 81-99. 
